\title{
Land Surface Water Coverage Estimation with PALSAR and AMSR-E for Large Scale Flooding Detection
}

\author{
$\mathrm{Xi} \mathrm{Li}^{*}$ and Wataru Takeuchi \\ Institute of Industrial Science, the University of Tokyo, Meguro, Tokyo, Japan
}

Received 2 June 2015, revised 11 November 2015, accepted 6 January 2016

\begin{abstract}
Land surface water cover (LSWC) PALSAR is obtained in this study by setting an inundated threshold using the interval estimation and Otsu's methods. By comparing the $\mathrm{HH}$ value $(\mathrm{dB})$ obtained using these two methods along with image interpretation, the $\mathrm{HH}$ value with $(\mu+3 \sigma)$ is considered the most reasonable inundation threshold. After masking with $\mu+3 \sigma$, LSWC of PALSAR was mapped and an exponential function with index NDFI (normalized difference frequent index) and NDPI (normalized difference polarization index) of AMSR-E corresponding to PALSAR LSWC was derived by applying the least squares method. It was found that the exponential regression curve could precisely represent the scatter points and the determination coefficient reached more than 0.8 . Both NDFI and NDPI have a good fitting result with PALSAR LSWC. Spatial correspondence is finally discussed between AMER-E NDFI/NDPI LSWC and PALSAR LSWC. A high correspondence is shown between each map. It was also found that PALSAR slightly underestimated the inundated area because of the different PALSAR and AMSR-E mechanisms. Using more precise AMSR-E calibration by PALSAR, the availability and potential of AMSR-E LSWC for large scale flooding detection is indicated.
\end{abstract}

Key words: NDFI, NDPI, Inundated threshold, Otsu's method, Calibration function

Citation: Li, X. and W. Takeuchi, 2016: Land surface water coverage estimation with PALSAR and AMSR-E for large scale flooding detection. Terr. Atmos. Ocean. Sci., 27, 473-480, doi: 10.3319/TAO.2016.01.06.01(ISRS)

\section{INTRODUCTION}

Global warming combined with excessive human activities has made flooding a severe and frequent disaster in recent years, arousing high attentions worldwide. Such flooding events have demonstrated the necessity to master real-time information and identify the development trends in large scale flooding worldwide.

Since flood events are dynamic processes, higher temporal microwave radiometer resolutions are necessary (Singh et al. 2013). AMSR-E, based on microwave observations can penetrate through clouds and provide long time daily global cover data series (Temimi et al. 2007). Large-scale flood patterns can be quickly revealed (Zheng et al. 2008). A multitemporal analysis of AMSR-E data for flood and discharge monitoring during the 2008 flood in Iowa was conducted by Temimi et al. (2011), demonstrating the importance passive microwave can play in monitoring flooding and wetness conditions and estimating key hydrological parameters.

\footnotetext{
* Corresponding author

E-mail:lixi@iis.u-tokyo.ac.jp
}

Chakraborty et al. (2011) used passive microwave signatures to detect and monitor flooding events in the Sundarban Delta. Watts et al. (2012) conducted a study of surface water inundation changes within the Arctic-Boreal Region and concluded that the AMSR-E fractional open water record corresponds strongly with regional wet/dry cycles inferred from basin discharge records. Takeuchi and Gonzalez (2009) predicted daily land surface water coverage by blending MODIS (Moderate Resolution Imaging Spectroradiometer) and AMSR-E and found that the algorithm accurately predicted daily LSWC (land surface water coverage) of AMSR-E. Moreover, studies on LSWC estimation with AMSR-E combined with MODIS have already been carried out (Takeuchi et al. 2006; Mori et al. 2009), but MODIS can be affected by clouds and cannot detect large scale flooding (Evans et al. 2010) because it conducts optical remote sensing. However, PALSAR, an active microwave sensor, provides high spatial resolution and is suitable to correspond to large scale flooding without cloud interruption (Alexakis et al.2012; Arnesen et al. 2013). To overcome the weakness of MODIS, which was commonly 
used, we utilized PALSAR to conduct more precise calibration to compensate AMSR-E for flooding detection.

The objective of this paper is to map the land surface water coverage of PALSAR. Moreover, finding the relationship between AMSR-E and PALSAR as a calibration function of index NDFI (normalized difference frequent index), NDPI (normalized difference polarization index) with physical quantity-LSWC derived from PALSAR.

\section{MATERIALS AND METHODS}

\subsection{Data Used in This Study}

AMSR-E data, with spatial resolution of $10 \mathrm{~km}$ and temporal resolution of 0.5 day were used to map NDFI/NDPI LSWC for flooding detection. Twelve flood events that occurred around the world (Fig. 1) were selected as research objects from the International charter. Base map is a global land surface water coverage distribution map resource derived from AMSR-E. Table 1 shows the basic information. PALSAR ScanSAR mode data, with a spatial resolution of $100 \mathrm{~m}$, were used to map LSWC and conduct calibration to AMSR-E. A detailed description of 4 PALSAR ScanSAR scenes used in this study is shown in Table 2.

\subsection{Selecting Inundated Threshold by Interval Estimation}

After pre-processing for the PALSAR ScanSAR image, we calculated the backscattering digital number coefficient as Eq. (1) shows.

$\sigma_{1.5}^{0}=10 \times \log _{10}\left(\mathrm{DN}^{2}\right)+\mathrm{CF}$

where DN: digital number of the amplitude image, CF: calibration factor.

After extracting 10 water area regions of interest (ROI), we calculated the mean $\mu$ (average) for backscattering (dB) and $\sigma$ (standard deviation) of each ROI. $\mu+\sigma, \mu+2 \sigma$, $\mu+3 \sigma, \mu+4 \sigma$ were then calculated to mask the water areas, respectively. The optimal range was then selected combined with image interpretation.

\subsection{Otsu's Method}

Otsu's method can automatically perform clusteringbased image thresholding, which is based on minimizing the weighted sum of within-class variances of the foreground and background pixels to establish an optimum threshold (Sezgin and Sankur 2004). Recall that minimization of within class variances is equal to the maximization of between-class scatter (Liao et al. 2001).

$$
\sigma_{\omega}^{2}(t)=\omega_{1}(t) \sigma_{1}^{2}(t)+\omega_{2}(t) \sigma_{2}^{2}(t)
$$

where weights $\omega_{i}$ : the probabilities of the two classes separated by a threshold; $t$ : threshold; $\sigma_{i}^{2}$ : variances of these classes.

The backscattering coefficient histogram of each PALSAR ScanSAR scene was built first. Each histogram was treated as an input and put into MATLAB to calculate the inundated threshold.

\subsection{LSWC Distribution Mapping of AMSR-E}

After carrying out a series of pre-processing steps including radiance calibration, geometric correction, and spatial mosaic, AMSR-E daily mosaics are used to compute the NDFI and NDPI. When atmospheric transmission is near 1 we can obtain NDFI, NDPI as follows (Mori et al. 2009; Takeuchi and Gonzalez 2009).

$\mathrm{NDFI}=\frac{\mathrm{TB}_{18.7 \mathrm{~V}}-\mathrm{TB}_{23.8 \mathrm{~V}}}{\mathrm{~TB}_{18.7 \mathrm{~V}}+\mathrm{TB}_{23.8 \mathrm{~V}}}$

where $\mathrm{TB}_{18.7 \mathrm{~V}}$ and $\mathrm{TB}_{23.8 \mathrm{v}}$ are the vertical $(\mathrm{V})$ polarization brightness temperatures at 18.7 and $23.8 \mathrm{GHz}$.

$\mathrm{NDPI}=\frac{\mathrm{TB}_{\mathrm{V}}-\mathrm{TB}_{\mathrm{h}}}{\mathrm{TB}_{\mathrm{V}}+\mathrm{TB}_{\mathrm{h}}}$

where $\mathrm{TB}_{\mathrm{V}}$ is the vertical polarization brightness temperature at $36.5 \mathrm{GHz} . \mathrm{TB}_{\mathrm{h}}$ is the horizontal polarization brightness temperature at $36.5 \mathrm{GHz}$.

\subsection{Calibrating AMSR-E with PALSAR by Regression Analysis}

After masking out the PALSAR image inundated area and aggregating the image into the same AMSR-E spatial resolution, which is $10 \mathrm{~km}$, we built the ROI and conducted spatial registration for PALSAR and AMSR-E. A calibration index function NDFI, NDPI corresponding to PALSAR LSWC was derived by applying the least squares method in MATLAB to express the relationship between AMSR-E and PALSAR. It is shown as an exponential Eq. (5).

$F(x)=\alpha \times \exp (b \times X)$

where $F(x)$ : PALSAR LSWC; $X$ : NDFI, NDPI.

\section{RESULT AND DISCUSSIONS}

\subsection{Selecting Inundated Threshold}

Interval estimation was conducted to derive the threshold based on statistical theory. Figure 2 is a PALSAR ScanSAR HH $\sigma_{1.5}^{0}(\mathrm{~dB})$ scene in Colombia in 2011/04/01. From 
this scene we chose the basin area and zoomed in as shown in Fig. 3e as a reference scene. Figures 3a, b, c, d are overlays of the water map in different masking ranges with the reference scene. Combined with image interpretation we can clearly see that with the increase in multiples, the masked out water area increased. This indicated that the water area was significantly underestimated by masking with $\mu+\sigma$, $\mu+2 \sigma$, whereas the water area was overestimated by masking with $\mu+4 \sigma$.

A mountain area was chosen next and zoomed in as

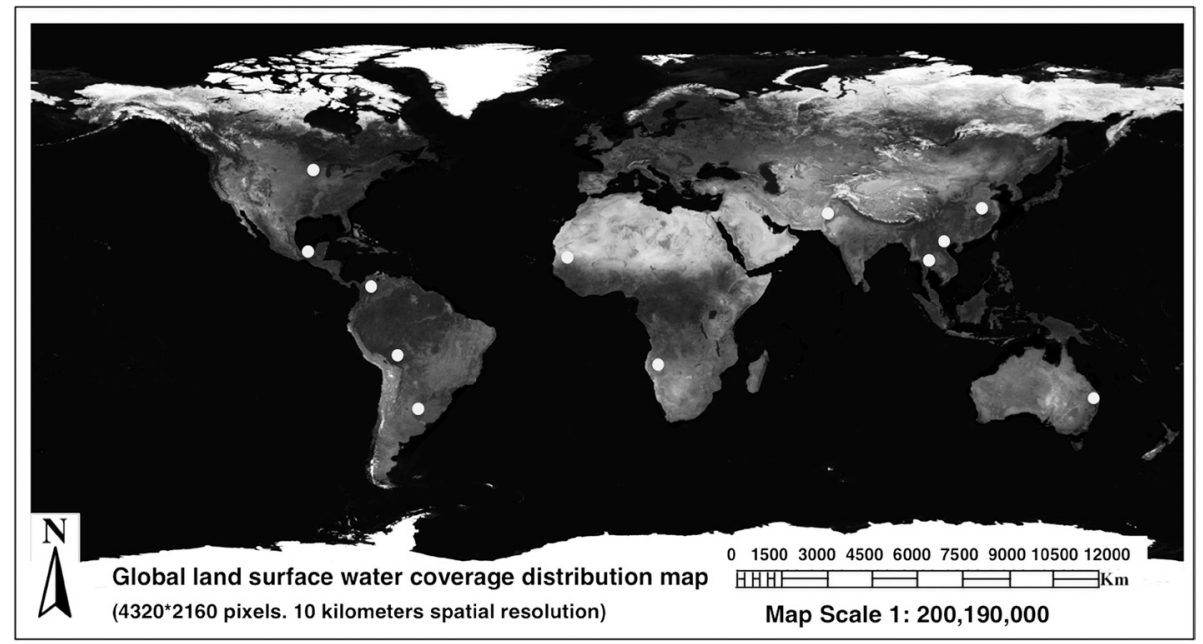

Fig. 1. Distribution of 12 flood events occurred in the worldwide selected from International charter.

Table 1. Basic information of 12 selected flood events.

\begin{tabular}{c|c|c|c|c}
\hline \multirow{2}{*}{ Country } & Location of Event & Date of Charter & \multicolumn{2}{c}{ Representative position } \\
\cline { 3 - 5 } & Activation & Latitude & Longitude \\
\hline Argentina & Santa Fe and Entre Rios provinces & $2007 / 03 / 30$ & $31.2^{\circ} \mathrm{S}$ & $60.6^{\circ} \mathrm{W}$ \\
China & Anhui province (Huai River basin) & $2007 / 07 / 13$ & $32.5^{\circ} \mathrm{N}$ & $115.8^{\circ} \mathrm{E}$ \\
Senegal & Kaolack & $2007 / 09 / 15$ & $16.1^{\circ} \mathrm{N}$ & $13.8^{\circ} \mathrm{W}$ \\
Mexico & Tabasco & $2007 / 11 / 02$ & $18.2^{\circ} \mathrm{N}$ & $92.5^{\circ} \mathrm{W}$ \\
Bolivia & Moxos, Beni and Marban provinces & $2008 / 01 / 25$ & $14.6^{\circ} \mathrm{S}$ & $65.1^{\circ} \mathrm{W}$ \\
USA & Iowa & $2008 / 06 / 12$ & $42.5^{\circ} \mathrm{N}$ & $93.2^{\circ} \mathrm{W}$ \\
Vietnam & North and Central provinces (Red River Delta Region) & $2008 / 11 / 05$ & $20.9^{\circ} \mathrm{N}$ & $105.8^{\circ} \mathrm{E}$ \\
Pakistan & North West Pakistan & $2010 / 08 / 02$ & $28.2^{\circ} \mathrm{N}$ & $69.4^{\circ} \mathrm{E}$ \\
Australia & Queensland & $2011 / 01 / 03$ & $27.3^{\circ} \mathrm{S}$ & $151.3^{\circ} \mathrm{E}$ \\
Namibia & Northern Namibia & $2011 / 04 / 01$ & $18.2^{\circ} \mathrm{S}$ & $15.7^{\circ} \mathrm{E}$ \\
Colombia & Bolivar province & $2011 / 05 / 22$ & $8.3^{\circ} \mathrm{N}$ & $73.9^{\circ} \mathrm{W}$ \\
Thailand & Central Thailand & $2011 / 10 / 17$ & $14.9^{\circ} \mathrm{N}$ & $100.3^{\circ} \mathrm{E}$ \\
\hline
\end{tabular}

Table 2. Detailed description of 4 PALSAR ScanSAR scenes.

\begin{tabular}{c|c|c|c|c|c|c}
\hline \multirow{2}{*}{ Location } & \multirow{2}{*}{ Observation data } & \multirow{2}{*}{ Polarization } & \multirow{2}{*}{ Orbit } & \multirow{2}{*}{ Spatial resolution } & \multicolumn{2}{|c}{ Scene Centre } \\
\cline { 6 - 7 } & & & & & Latitude & Longitude \\
\hline Mexico & $2007 / 11 / 03$ & $\mathrm{HH}$ & Descending & $100 \mathrm{~m}$ & $18.1^{\circ} \mathrm{N}$ & $91.0^{\circ} \mathrm{W}$ \\
Vietnam & $2008 / 11 / 05$ & $\mathrm{HH}$ & Descending & $100 \mathrm{~m}$ & $20.8^{\circ} \mathrm{N}$ & $106.0^{\circ} \mathrm{E}$ \\
Australia & $2011 / 01 / 09$ & $\mathrm{HH}$ & Ascending & $100 \mathrm{~m}$ & $27.8^{\circ} \mathrm{S}$ & $151.6^{\circ} \mathrm{E}$ \\
Colombia & $2011 / 04 / 01$ & $\mathrm{HH}$ & Descending & $100 \mathrm{~m}$ & $8.2^{\circ} \mathrm{N}$ & $74.2^{\circ} \mathrm{W}$ \\
\hline
\end{tabular}




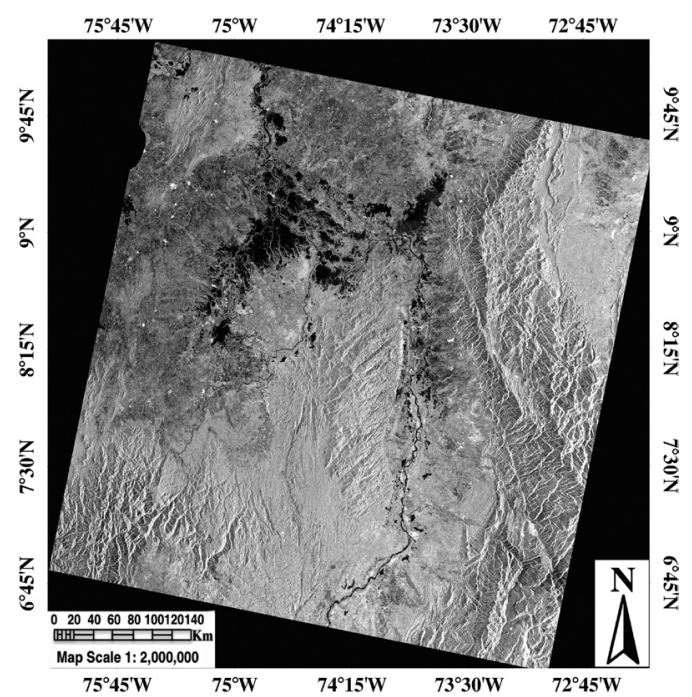

Fig. 2. PALSAR ScanSAR HH $\sigma_{1.5}^{0}(\mathrm{~dB})$ scene in Colombia in 2011/04/01.

(a)

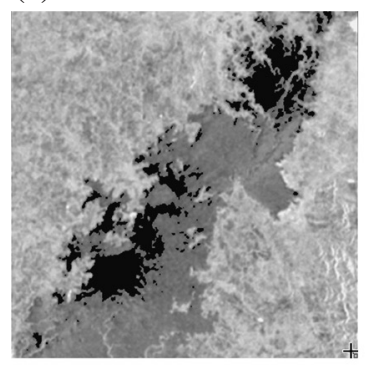

(d)

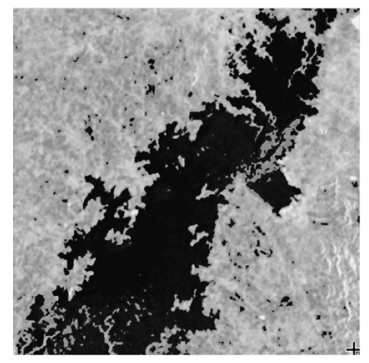

(b)

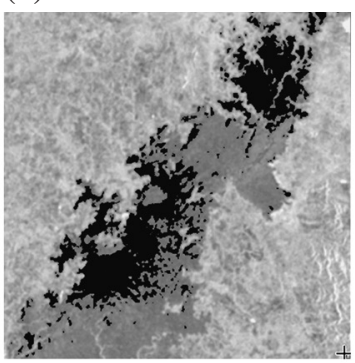

(e) $73^{\circ} 55^{\circ} \mathrm{W} 73^{\circ} 50^{\circ} \mathrm{W} 73^{\circ} 45 \mathrm{~W} 73^{\circ} 40 \mathrm{~W}$

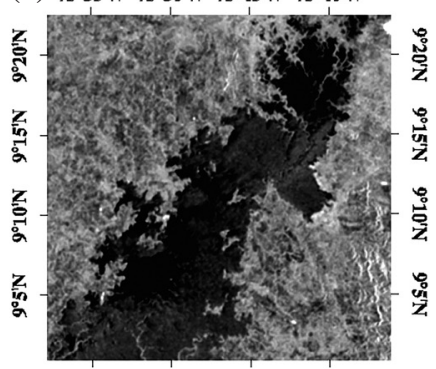

$73^{\circ} 55^{\circ} \mathrm{W} 73^{\circ} 50 \mathrm{~W} 73^{\circ} 45 \mathrm{~W} 73^{\circ} 40 \mathrm{~W}$ (c)

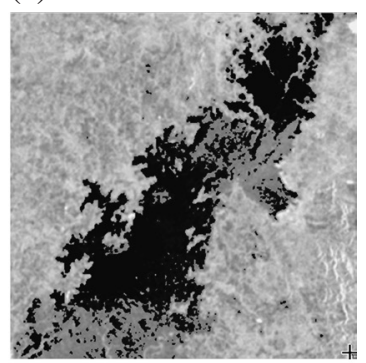

Fig. 3. Overlays of water map in different masking ranges with reference ScanSAR HH $\sigma_{1.5}^{0}$ (dB). (a) $\mu+\sigma(d B) ;(b) \mu+2 \sigma(d B)$; (c) $\mu+3 \sigma(d B)$; (d) $\mu+4 \sigma(\mathrm{dB})$; (e) Reference ScanSAR HH $\sigma_{1.5}^{0}(\mathrm{~dB})$.

shown in Fig. 4a to discuss. Figure $4 \mathrm{~b}$ is the water map masking with $\mu+4 \sigma$. In comparison with the Google Earth image we can see that some valleys were also masked out as water areas. It can be proven that on masking with $\mu+4 \sigma$ range, the inundated area was overestimated.

We utilized Otsu's method to obtain the inundated threshold based on a backscatter coefficient histogram. Figure 5 shows a backscatter histogram coefficient derived from PALSAR HH scenes in Australia and Vietnam.

Table 3 shows a comparison of the inundation threshold derived using the two methods. By comparing $\mathrm{dB}$ we found that the results obtained using interval estimation with $\mu+3 \sigma$ and Otsu's method were statistically identical. The difference in value is smaller than $0.5 \mathrm{~dB}$ in Australia, Vietnam, and Mexico. However, when the target and the background vary greatly in size proportion disparity Otsu's method does not work so well sometimes (Zhang et al. 2011). We therefore defined the $\mathrm{HH}$ value with $\mu+3 \sigma$ as the inundation threshold in this research.

On comparison with different scenes some variations in $\sigma_{1.5}^{0}(\mathrm{~dB})$ have been found. We considered that the research area is located in a different land use land cover type. Since 
(a)

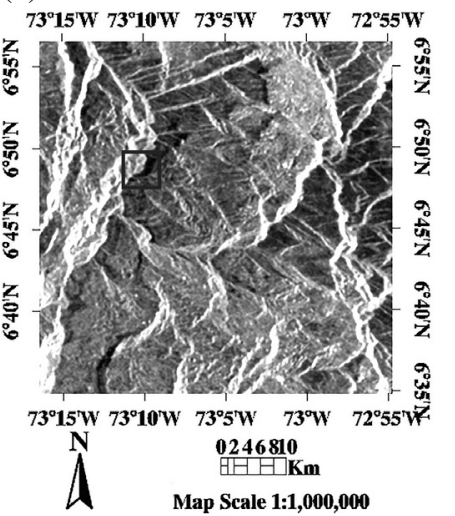

(b)

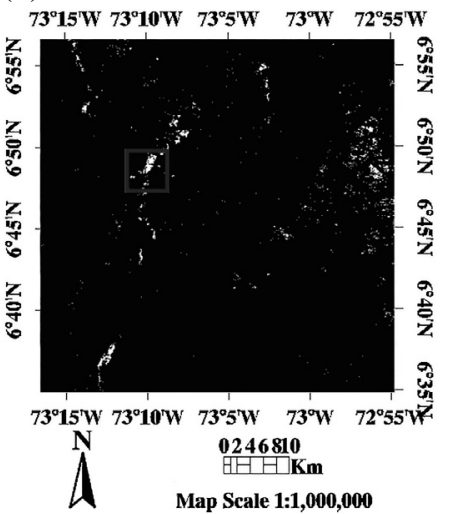

(c)

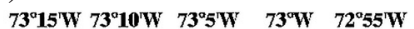

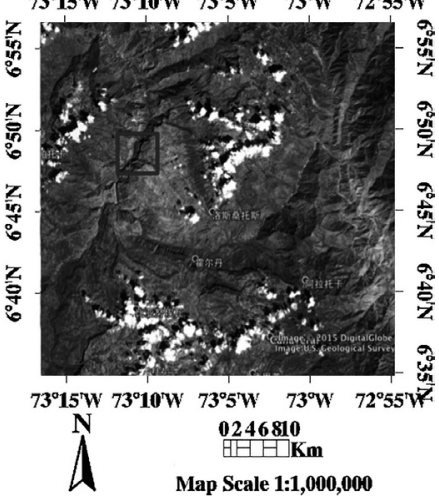

Fig. 4. Image interpretation of PALSAR scene in mountain area by masking with $\mu+4 \sigma$. (a) PALSAR ScanSAR HH $\sigma_{1.5}^{0}$ (dB); (b) Water area masking with $\mu+4 \sigma$; (c) Google Earth Map.

(a)

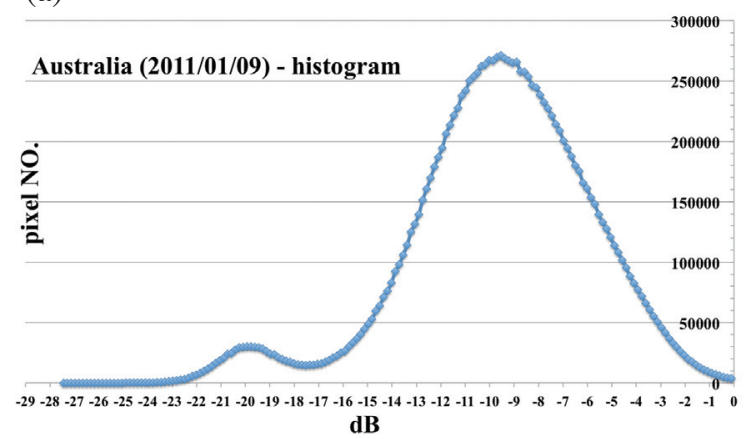

(b)

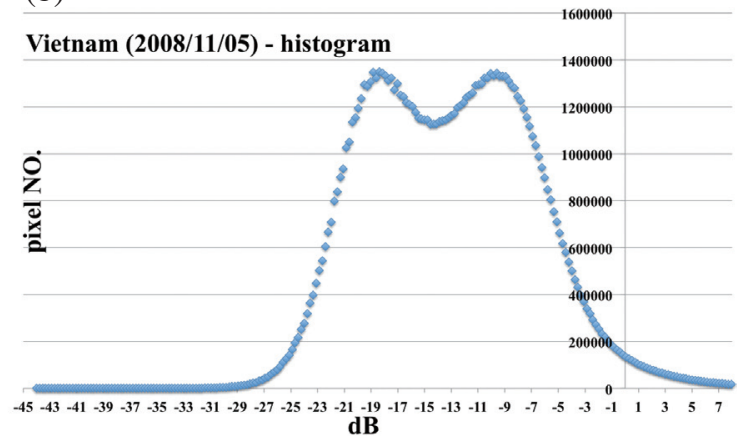

Fig. 5. Histogram of backscattering coefficient derived from two PALSAR HH scenes. (a) Australia (2011/01/09); (b) Vietnam (2008/11/05). (Color online only)

Table 3. Comparison of inundated threshold derived by interval estimation and Otsu's method.

\begin{tabular}{c|cccc}
\hline & Colombia & Australia & Vietnam & Mexico \\
\hline$\mu+\sigma(\mathrm{dB})$ & -23.05 & -20.10 & -20.69 & -21.85 \\
$\mu+2 \sigma(\mathrm{dB})$ & -21.50 & -19.09 & -18.32 & -20.77 \\
$\mu+3 \sigma(\mathrm{dB})$ & -20.12 & -18.06 & -15.50 & -19.69 \\
$\mu+4 \sigma(\mathrm{dB})$ & -17.65 & -17.00 & -13.50 & -18.61 \\
Otsu's method $(\mathrm{dB})$ & -21.80 & -17.90 & -15.45 & -19.43 \\
\hline
\end{tabular}

the PALSAR mechanism is backscattering the surface roughness and vegetation affect its performance. This leads to some variation in $\mu$ in different cases. In addition, the incidence angle is a backscattering influence factor for the PALSAR ScanSAR image. Based on our previous research we found that within small range of incidence angles the incidence angle effect is within the acceptable $\sigma_{1.5}^{0}(\mathrm{~dB})$ variation for PALSAR. In view of whole scene, from $\mathrm{N}$ to $\mathrm{F}$ range, a constant variation could be seen ( $\mathrm{Li}$ and Takeuchi 2015). We considered selecting the optimal threshold with a combination of omission and commission based on our objective.

\subsection{Relationship Between NDFI/NDPI and PALSAR LSWC}

According to the above result we use the confidence interval $(\mu-3 \sigma, \mu+3 \sigma)$ to mask out the PALSAR image inundation area.

Figure 6 shows a scatter plot of two cases in Mexico and Colombia, which represent the relationship between AMSR-E NDFI/NDPI and PALSAR LSWC. From Fig. 6 and Table 4 the exponential regression curve could precisely represent the scatter points and the determination 
(a)

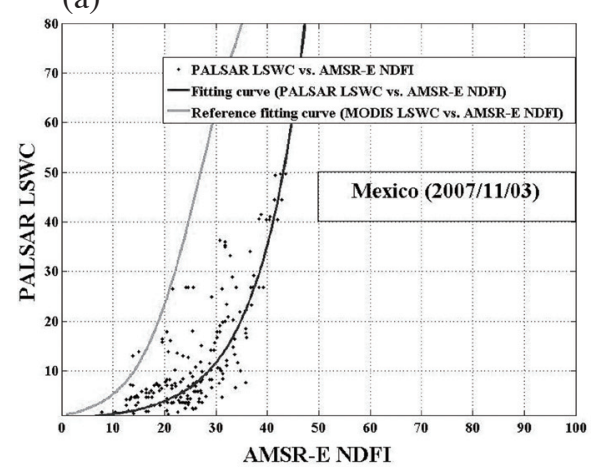

(c)

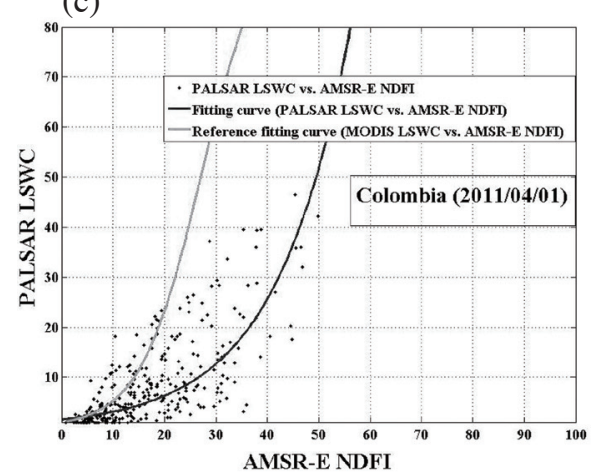

(b)

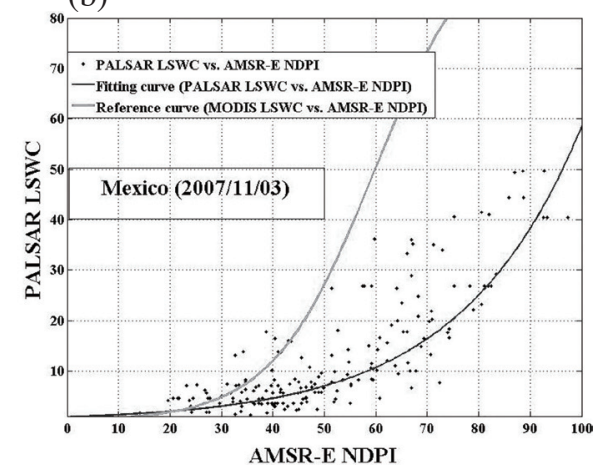

(d)

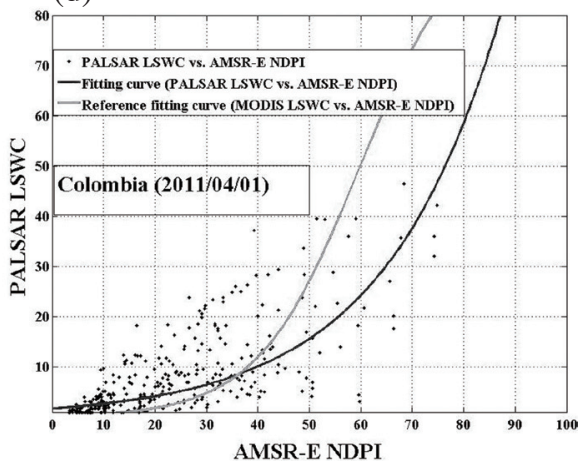

Fig. 6. Scatter plot representing the relation between AMSR-E NDFI/NDPI and PALSAR LSWC. (a) NDFI-PALSAR (Mexico); (b) NDPI-PALSAR (Mexico); (c) NDFI-PALSAR (Colombia); (d) NDPI-PALSAR (Colombia).

Table 4. Results of coefficients a, b, and standard deviation.

\begin{tabular}{c|cc|cc}
\hline \multirow{2}{*}{} & \multicolumn{2}{|c|}{ Mexico (2007/11/03) } & \multicolumn{2}{c}{ Colombia (2011/04/01) } \\
\cline { 2 - 5 } & NDFI-PALSAR & NDPI-PALSAR & NDFI-PALSAR & NDPI-PALSAR \\
\hline a & 1.850 & 2.137 & 1.599 & 2.006 \\
b & 0.056 & 0.025 & 0.064 & 0.036 \\
R-square & 0.961 & 0.962 & 0.897 & 0.822 \\
RMSE & 2.614 & 2.693 & 1.987 & 2.588 \\
\hline
\end{tabular}

Note: Coefficients (with 95\% confidence bounds).

coefficient reached more than 0.8. Both NDFI and NDPI have a good fitting result with PALSAR LSWC. Compared with NDFI and NDPI the same PALSAR LSWC corresponds to a bigger value of AMSR-E NDPI. For the reason that NDPI was calculated using brightness temperature with higher frequency $-36.5 \mathrm{GHz}$, which can lead to a stronger penetration, NDPI was more likely to be affected by the surface roughness.

Based on the research by Mori et al. (2009) they estimated LSWC with AMSR-E and MODIS, and found the relationship between AMSR-E NDPI and MODIS LSWC (Mori et al. 2009). According to the logistical function they developed, we added a regression curve as the red line shows in Fig. 6 for comparison. Based on this result we can see that in this research the curve between AMSR-E and PALSAR can better represent scatter than the curve between AMSR-
E and MODIS.

\subsection{Spatial Correspondence Between AMER-E NDFI/ NDPI LSWC Distribution Map and PALSAR LSWC Distribution Map}

Spatial correspondence between AMSR-E NDFI/NDPI and PALSAR LSWC was discussed by comparing the LSWC distribution map of each. In a previous study an NDFI, NDPI database in time series from 2002 - 2011 derived from AMSR-E was built with an NDFI/NDPI LSWC distribution map (Li and Takeuchi 2014a, b). Figures 7 and 8 show the spatial correspondence between AMSR-E NDFI/NDPI LSWC distribution maps with the PALSAR LSWC distribution maps in Mexico and Colombia on the same day, respectively. Among them, Figs. 7a and 8a are the AMSR-E NDFI LSWC 

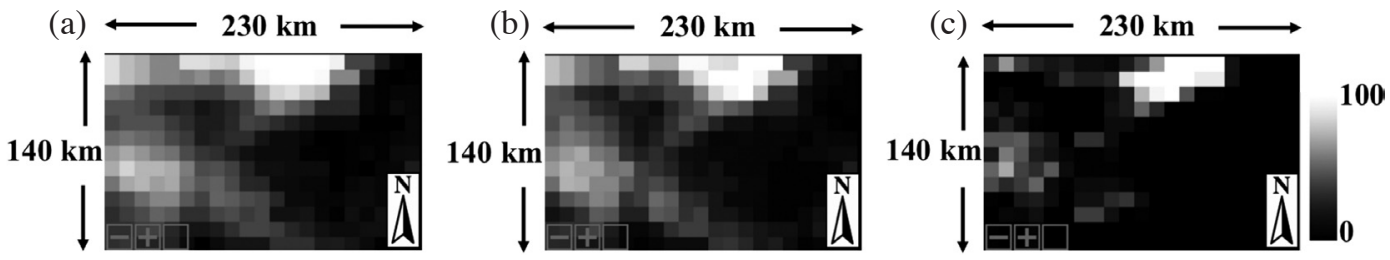

Fig. 7. Spatial correspondence of AMSR-E NDFI/NDPI LSWC distribution map with PALSAR LSWC distribution map in Mexico (2007/11/03). Brighter area indicates high abundance of water coverage at that pixel. (a) AMSR-E NDFI LSWC (10 km resolution); (b) AMSR-E NDPI LSWC (10 km resolution); (c) PALSAR ScanSAR LSWC (10 km resolution).
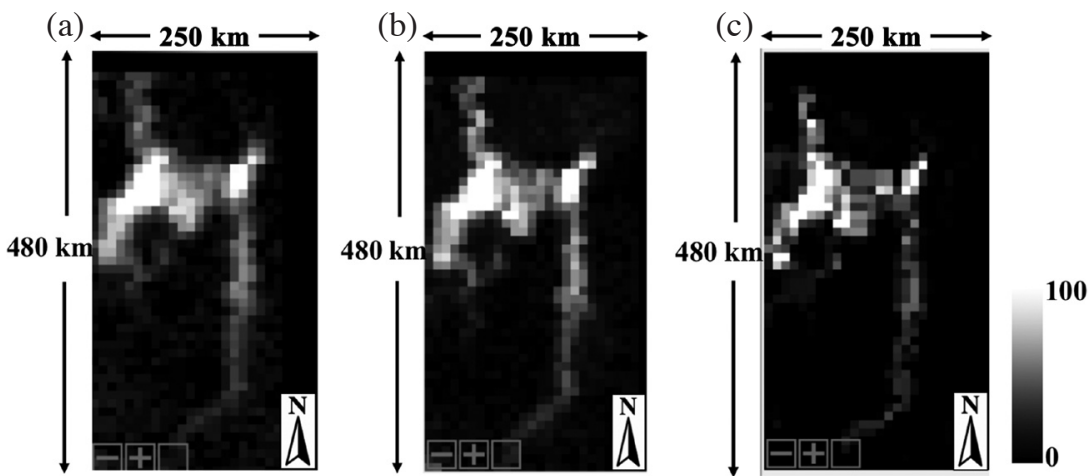

Fig. 8. Spatial correspondence of AMSR-E NDFI/NDPI LSWC distribution map with PALSAR LSWC distribution map in Colombia (2011/04/01). Brighter area indicates high abundance of water coverage at that pixel. (a) AMSR-E NDFI LSWC (10 km resolution); (b) AMSR-E NDPI LSWC (10 km resolution); (c) PALSAR ScanSAR LSWC (10 km resolution).

distribution maps. Figures $7 \mathrm{~b}$ and $8 \mathrm{~b}$ are the AMSR-E NDPI LSWC distribution maps. Figures $7 \mathrm{c}$ and $8 \mathrm{c}$ show the PALSAR LSWC distribution maps, conducted using layer stacking with AMSR-E images to obtain the same area resized into the same spatial resolution with AMSR-E. The brighter area indicates a high abundance of water coverage at that pixel. A good agreement between AMSR-E NDFI, NDPI and PALSAR LSWC can be seen. The LSWC distribution images visually match each other.

At the same time, in the Mexico case, some spatial variation can be found between the PALSAR LSWC and AMSR-E NDFI, NDPI LSWC distribution maps. Combined with the Google Earth map we found that the land use and land cover of the research area is complicated. As we know, the PALSAR mechanism is backscattering, whereas the AMSR-E mechanism is brightness temperature. Although they both belong to microwave remote sensing regimes, their mechanisms are totally different. Therefore, PALSAR will slightly underestimate the inundated area due the influence of surface roughness and vegetation. The emitted AMSR-E microwave signal is sensitive to both the water and soil moisture. It is difficult to distinguish clearly between wetness and flooding using the relatively low spatial resolution. The inundated area will be slightly overestimated.

\section{CONCLUSIONS AND FUTURE WORK}

We succeeded in selecting the inundation threshold based on interval estimation and Otsu's method. Moreover, a LSWC distribution map for PALSAR was mapped. A calibration function was established to show a good relationship between NDFI, NDPI of AMSR-E and LSWC derived from PALSAR. It indicated the availability and potential of AMSR-E LSWC to detect large scale flooding worldwide.

This study focused only on open water areas. In future work we will advance to investigate the above vegetation effects on microwaves. Moreover, AMSR2 and PALSAR2 will be used to link up with the current research.

\section{REFERENCES}

Alexakis, D. D., D. G. Hadjimitsis, A. Agapiou, K. Themistocleous, A. Retalis, S. Michaelides, S. Pashiardis, and F. Tymvios, 2012: Flood mapping of Yialias River catchment area in Cyprus using ALOS PALSAR radar images. Proc. SPIE, 8531, doi: 10.1117/12.974581. [Link]

Arnesen, A. S., T. S. F. Silva, L. L. Hess, E. M. L. M. Novo, C. M. Rudorff, B. D. Chapman, and K. C. McDonald, 2013: Monitoring flood extent in the lower Amazon River floodplain using ALOS/PALSAR ScanSAR images. Remote Sens. Environ., 130,51-61, doi: 10.1016/j. rse.2012.10.035. [Link] 
Chakraborty, R., R. Rahmoune, and P. Ferrazzoli, 2011: Use of passive microwave signatures to detect and monitor flooding events in Sundarban Delta. 2011 IEEE International Geoscience and Remote Sensing Symposium (IGARSS), IEEE, 3066-3069, doi: 10.1109/ IGARSS.2011.6049865. [Link]

Evans, T. L., M. Costa, K. Telmer, and T. S. F. Silva, 2010: Using ALOS/PALSAR and RADARSAT-2 to map land cover and seasonal inundation in the Brazilian Pantanal. IEEE J-STARS, 3, 560-575, doi: 10.1109/ JSTARS.2010.2089042. [Link]

Li, X. and W. Takeuchi, 2014a: Flood analysis and forecasting by spatio-temporal data mining based on historical satellite image database. The 35th Asian Conference of Remote Sensing (ACRS), Nay Pyi Taw, Myanmar, $6 \mathrm{pp}$.

Li, X. and W. Takeuchi, 2014b: Flood event detection by AMSR-E and PALSAR on global scale. The International Symposium on Remote Sensing (IRSR), Busan, Korea.

Li, X. and W. Takeuchi, 2015: Global flood detection and spatio-temporal analysis from 2002-2015 by AMSR-E, Windsat and AMSR2. The 36th Asian Conference of Remote Sensing (ACRS), Manila, Philippines, $10 \mathrm{pp}$.

Liao, P. S., T. S. Chen, and P. C. Chung, 2001: A fast algorithm for multilevel thresholding. J. Inform. Sci. Eng., 17, 713-727.

Mori, S., W. Takeuchi, and H. Sawada, 2009: Estimation of land surface water coverage (LSWC) with AMSR-E and MODIS. Proceedings of 2nd Joint Student Seminar on Civil Infrastructures, AIT, Bangkok Thailand.

Sezgin, M. and B. Sankur, 2004: Survey over image thresholding techniques and quantitative performance evaluation. J. Electron. Imag., 13, 146-168, doi: 10.1117/1.1631315. [Link]

Singh, Y., P. Ferrazzoli, and R. Rahmoune, 2013: Flood monitoring using microwave passive remote sensing (AMSR-E) in part of the Brahmaputra basin,
India. Int. J. Remote Sens., 34, 4967-4985, doi: 10.1080/01431161.2013.786194. [Link]

Takeuchi, W. and L. Gonzalez, 2009: Blending MODIS and AMSR-E to predict daily land surface water coverage. International Remote Sensing Symposium (ISRS), Busan, South Korea.

Takeuchi, W., D. Komori, T. Oki, and Y. Yasuoka, 2006: An integrated approach on rice paddy irrigation pattern monitoring over Asia with MODIS and AMSR-E. American Geophysical Union, Fall Meeting 2006, abstract \#B41B-0188, San Francisco, USA.

Temimi, M., R. Leconte, F. Brissette, and N. Chaouch, 2007: Flood and soil wetness monitoring over the Mackenzie River Basin using AMSR-E $37 \mathrm{GHz}$ brightness temperature. J. Hydrol., 333, 317-328, doi: 10.1016/j.jhydrol.2006.09.002. [Link]

Temimi, M., T. Lacava, T. Lakhankar, V. Tramutoli, H. Ghedira, R. Ata, and R. Khanbilvardi, 2011: A multitemporal analysis of AMSR-E data for flood and discharge monitoring during the 2008 flood in Iowa. Hydrol. Process., 25, 2623-2634, doi: 10.1002/hyp.8020. [Link]

Watts, J. D., J. S. Kimball, L. A. Jones, R. Schroeder, and K. C. McDonald, 2012: Satellite Microwave remote sensing of contrasting surface water inundation changes within the Arctic-Boreal Region. Remote Sens. Environ., 127, 223-236, doi: 10.1016/j.rse.2012.09.003. [Link]

Zhang, G., S. Chen, and J. Liao, 2011: Otsu image segmentation algorithm based on morphology and wavelet transformation. $20113^{\text {rd }}$ International Conference on Computer Research and Development (ICCRD), IEEE, Shanghai, 279-283, doi: 10.1109/ICCRD.2011.5764020. [Link]

Zheng, W., C. Liu, Z. Xin, and Z. Wang, 2008: Flood and waterlogging monitoring over Huaihe River Basin by AMSR-E data analysis. Chin. Geogr. Sci., 18, 262-267, doi: 10.1007/s11769-008-0262-7. [Link] 